\title{
Prevalence of Gingival Pigmentation and its Psychological Effect in Chennai Population
}

\author{
Prashaanthi. $\mathrm{N}^{1}$ and Kaarthikeyan. $\mathrm{G}^{2}$ \\ ${ }^{1}$ Saveetha Dental College and Hospitals, Saveetha Institute of Medical \\ and Technical Sciences(SIMATS), Saveetha University, Chennai, India \\ ${ }^{2}$ Professor, Department of Periodontics, Saveetha Dental College and Hospitals, \\ Saveetha Institute of Medical and Technical Sciences(SIMATS), Saveetha University, \\ Chennai, India
}

\section{ABSTRACT}

Esthetic concerns are increasing among individuals and gingival esthetics have an integral part in the patient's smile. Gingival pigmentation can affect the patients psychologically and their social interaction. The aim of study was to assess the prevalence of gingival pigmentation and psychological behaviour among patients. This study included 150 patients in a dental hospital. Pre tested questionnaire was distributed among the patients with gingival pigmentation. Data was tabulated and results were obtained. Descriptive and chi square statistics were performed. In our study, out of 150 patients , 62\% were under $18-25$ years and 38\% were $26-35$ years. $43.3 \%$ were males and $56.7 \%$ were females. 81.3\% were aware of the gingival pigmentation and 25.3\% felt uncomfortable with their esthetics while smiling. 19.3\% of the study population were willing to undergo treatment for pigmentation while $87.3 \%$ were not affected with social interactions. There was a statistically significant association of patients' awareness about gingival pigmentation among different age and gender $(p<0.05)$. Within the limitations of the present study, younger adults had more esthetic concern when compared to adolescents. Males were more willing to undergo treatment when compared to females.

\section{KEY WORDS: GINGIVAL PIGMENTATION;ESTHETICS;MELANIN;PSYCHOLOGICAL;SOCIAL INTERACTION.}

\section{INTRODUCTION}

Gingival hyperpigmentation is the partial or complete darkening of gingiva in contrast to the coral pink colour of normal gingiva. The excessive melanin deposition in the basal and suprabasal cell layers of the epithelium leads to hyperpigmentation of gingiva . (Goswami et al., no date; Hatch, 2005). Melanocytes are dendritic cells of neuroectodermal origin. They work independent of the

\section{ARTICLE INFORMATION}

*Corresponding Author: kaarthikeyan@saveetha.com Received 26th July 2020 Accepted after revision 21th Sep 2020 Print ISSN: 0974-6455 Online ISSN: 2321-4007 CODEN: BBRCBA

Thomson Reuters ISI Web of Science Clarivate Analytics USA and Crossref Indexed Journal

\section{Clarivate
Analytics}

NAAS Journal Score 2020 (4.31) SJIF: 2020 (7.728)

A Society of Science and Nature Publication,

Bhopal India 2020. All rights reserved.

Online Contents Available at: http//www.bbrc.in/

Doi: $h t t p: / / d x$.doi.org/10.21786/bbrc/13.8/143 surrounding epithelial cells and behave as unicellular exocrine glands, converting tyrosine to melanin protein (melanin), which is transferred to keratinocytes by way of melanosomes. Thus, the melanin is deposited in the basal layer of the oral epithelium. (Esen et al., 2004; Arikan and Gürkan, 2007)

Pigmentation is caused by the physiological process such as melanin, melanoid, carotene, oxyhemoglobin, reduced hemoglobin, bilirubin and iron and/or pathological diseases, and conditions. Melanin pigmentation occurs when melanoblasts produce melanin granules. And environmental risk factors such as forms of tobacco have an essential role in the gingival hyperpigmentation. The colour of the gingiva is influenced by ethnicity and age. (Alasmari, 2018)

Light brown to black pigmentation is considered as physiologic in healthy colored-skinned individuals,

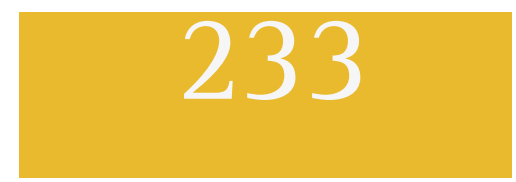


whereas the same oral pigmentation in Caucasians is considered as abnormal. Individual's genetics play a vital role in the development of gingival pigmentation. The physical, chemical, and hormonal factors are responsible for the intensity of pigmentation.(Peeran et al., 2014) Hyperpigmentation is also associated with various disorders such as Albright syndrome, malignant melanoma, PeutzJeghers syndrome, trauma, hemochromatosis, chronic pulmonary disease, HIV, smoking and use of antimalarial drugs, oral contraceptives (Hatch, 2005) There are various indices for classification of gingival pigmentation and pigmented lesions among individuals.(Shahna et al., 2019).Based on the severity of the pigmentation, the treatment modalities change accordingly.

Pigmentation of gingiva creates a psychological impact on the patients and is considered to be unaesthetic by patients (Alasmari, 2018). The hyperpigmentation of the gingiva on the labial aspect of anterior teeth has become an important component of general esthetics. (Peeran et al., 2014). A beautiful smile surely enhances the individual's self-confidence. The harmony of smile and esthetics is generally attributable to the shape, colour, and position of the teeth in conjunction with the gingival tissue. Gingival health and appearance are essential components for an attractive smile and depigmentation of the unsightly pigmented gingiva is the need for a pleasant and confident smile. (Grover et al., 2014; Sedeh, Badihi and Esfahaniyan, 2014)

Gingival pigmentation though not a major complication, yet it greatly affects the facial appearance. They might affect the individual psychologically and interfere with their interactions with the peers. Nowadays younger generations are greatly influenced by facial appearance and they are cautious about their esthetic concern and presentation of themselves in the society. Previously we have worked on plenty of topics in periodontology (Ramesh, Ravi and Kaarthikeyan, 2017; Ravi et al., 2017; Arjunkumar, 2018; Jain and Nazar, 2018; Kavarthapu and Thamaraiselvan, 2018; Ramamurthy and Mg, 2018; Ramesh et al., 2018, 2019; Ezhilarasan, Apoorva and Ashok Vardhan, 2019; Kaarthikeyan, Jayakumar and Sivakumar, 2019; Kavarthapu and Malaiappan, 2019; Murthykumar, Arjunkumar and Jayaseelan, 2019; Vijayashree Priyadharsini, 2019). Now we are planning to assess the prevalence of gingival pigmentation and psychological behaviour among patients in Chennai.

\begin{tabular}{|c|c|c|c|}
\hline Questions & Responses & Frequency & Percentage \\
\hline \multirow[t]{2}{*}{ AGE } & $18-25$ & 93 & 62 \\
\hline & $26-30$ & 57 & 38 \\
\hline \multirow[t]{2}{*}{ GENDER } & MALE & 65 & 43.3 \\
\hline & FEMALE & 85 & 56.7 \\
\hline $\begin{array}{l}\text { ARE YOU AWARE OF } \\
\text { GINGIVAL PIGMENTATION }\end{array}$ & YES & 122 & 81.3 \\
\hline IN YOUR GUMS & NO & 28 & 18.7 \\
\hline \multirow{3}{*}{$\begin{array}{l}\text { DID YOU NOTICE } \\
\text { PIGMENTATION IN YOUR GUMS }\end{array}$} & YES & 117 & 78 \\
\hline & & & \\
\hline & NO & 33 & 22 \\
\hline \multirow[t]{2}{*}{ DO YOU FEEL UNCOMFORTABLE TO SMILE } & YES & 38 & 25.3 \\
\hline & NO & 112 & 74.7 \\
\hline DO YOU FEEL THIS PIGMENTATION LIMITS & 19 & 12.7 & \\
\hline \multirow[t]{2}{*}{ YOUR INTERACTION WITH OTHERS } & YES & & \\
\hline & NO & 131 & 87.3 \\
\hline \multirow[t]{2}{*}{$\begin{array}{l}\text { HAVE YOUR PEERS NOTICED YOUR } \\
\text { PIGMENTATION }\end{array}$} & $\begin{array}{c}0 \\
\text { YES }\end{array}$ & 0 & \\
\hline & NO & 150 & 100 \\
\hline \multirow{2}{*}{$\begin{array}{l}\text { DOES THIS NEGATIVELY AFFECT } \\
\text { YOUR CONFIDENCE }\end{array}$} & YES & 44 & 29.3 \\
\hline & NO & 106 & 70.7 \\
\hline \multirow{3}{*}{$\begin{array}{l}\text { ARE YOU WILLING TO UNDERGO ANY } \\
\text { TREATMENT FOR YOUR PIGMENTATION }\end{array}$} & 29 & 19.3 & \\
\hline & YES & & \\
\hline & NO & 121 & 80.7 \\
\hline \multirow{4}{*}{$\begin{array}{l}\text { ARE YOU AWARE THAT EVEN AFTER } \\
\text { TREATMENT , THERE IS CHANCES OF } \\
\text { RECURRENCE FOR GINGIVAL PIGMENTATION }\end{array}$} & YES & 17 & 11.3 \\
\hline & & & \\
\hline & & & \\
\hline & NO & 133 & 88.7 \\
\hline
\end{tabular}




\section{MATERIAL AND METHODS}

The study was done among the patients with gingival pigmentation of the Chennai population. Institutional review board approval was obtained for this survey based analysis. 2 reviewers [Primary investigator \& guide] were involved in this study. The sample size of 150 participants of age group 18-35 years, both males and females were selected by a simple random sampling method. Patients with gingival pigmentation were assessed based on Peeran et al(Peeran et al., 2014) .Randomisation [for all variables] was followed to minimise the bias. Pre tested questionnaires where the internal validity was the homogenisation and replication of experiment. Cross verification with existing studies was the external validity of this study. The set of questionnaires which includes gender, questions on gingival pigmentation and their psychological behaviour were circulated among the participants through an questionnaire.The results were collected and tabulated. Then the results were exported for statistical analysis to SPSS statistical software. Both descriptive ( frequency of the responses) and inferential statistics (Chi - square tests) were done and the results were presented in the forms of graphs.

\section{RESULTS AND DISCUSSION}

In the present study, out of 150 patients, $62 \%$ were under $18-25$ years and 38\% were under 26-35 years. Out of 150 patients with gingival pigmentation, $43.33 \%$ were males and $56.67 \%$ were females [Table 1]. On assessing the percentage of patients aware about gingival pigmentation, 81.33\% were aware of gingival pigmentation while $18.67 \%$ were not aware about gingival pigmentation. When asked by patients about their pigmentation, 78\% have noticed their pigmentation while $22 \%$ have not noticed their pigmentation. On analysing the patient's response whether gingival pigmentation affected their smile, $74.67 \%$ were not uncomfortable to smile while 25.33\% felt uncomfortable while smiling [Table 1].

On assessing the percentage of patients with gingival pigmentation and their interaction with others, $87.33 \%$ did not have any limitation while interacting with others while $12.67 \%$ had limited interaction. When asked about the percentage of patients responses about their confidence, $70.67 \%$ of patients confidence was not affected while $29.33 \%$ of patients confidence was affected [Table 1]. On assessing the percentage of patients willingness to undergo treatment for gingival pigmentation, 19.33\% were willing to undergo treatment for gingival pigmentation while $80.67 \%$ were not willing to undergo treatment. [Table 1]

On statistical analysing, the association between the awareness of gingival pigmentation among different age groups, 54\% under 18-25 years and 27.33\% under 26-35 years were aware about gingival pigmentation. There was a statistically significant association between the gingival pigmentation among different age groups, $\mathrm{p}$ value $=0.000$. [Figure 1] On statistically analysing the association between patients' comfort to smile among different age groups, 25.33\% under 18-25 years felt uncomfortable while smiling due to gingival pigmentation. There was a statistically significant association between patients' comfort to smile among different age groups, $\mathrm{p}$ value $=0.000$ [Figure 2]. On statistically analysing the association between patients' confidence among different age groups, $29.33 \%$ under 18-25 years felt gingival pigmentation affected the confidence. There was a statistically significant association between patients' confidence among different age groups, $p$ value $=0.000$ [Figure 3].

Figure 1: Bar graph shows the association of awareness of gingival pigmentation among different age groups. $\mathrm{X}$ axis - age in years ; $\mathrm{Y}$ axis - number of patients. 54\% under 18-25 years (blue) and 27.33\% under 26-35 years (blue) were aware about gingival pigmentation. There was a statistically significant association found. (Pearson chi square $=5.355 \mathrm{a}, \mathrm{p}$ value $=0.021$ )

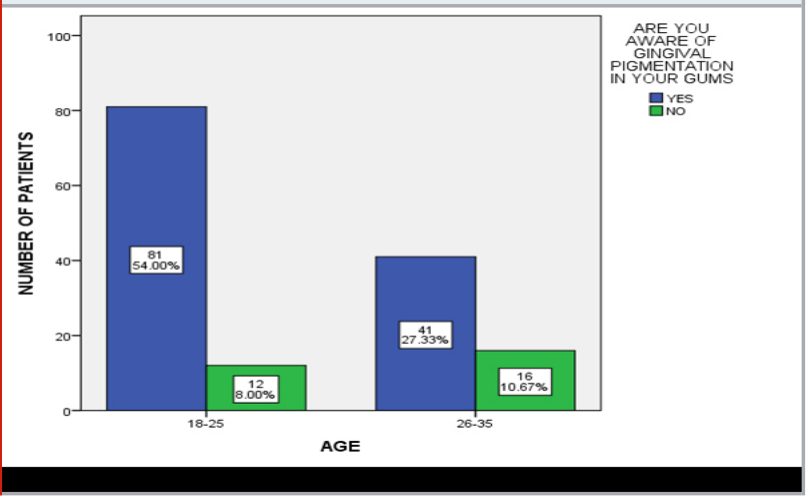

Figure 2: Bar graph shows the association between patients' smile and different age groups. $\mathrm{X}$ axis - age in years ; Y axis - number of patients. 25.33\% under 1825 years (blue) felt uncomfortable while smiling due to gingival pigmentation. There was a statistically significant association found. (Pearson chi square $=31.192 \mathrm{a}, \mathrm{p}$ value $=\mathbf{0 . 0 0 0}$ )

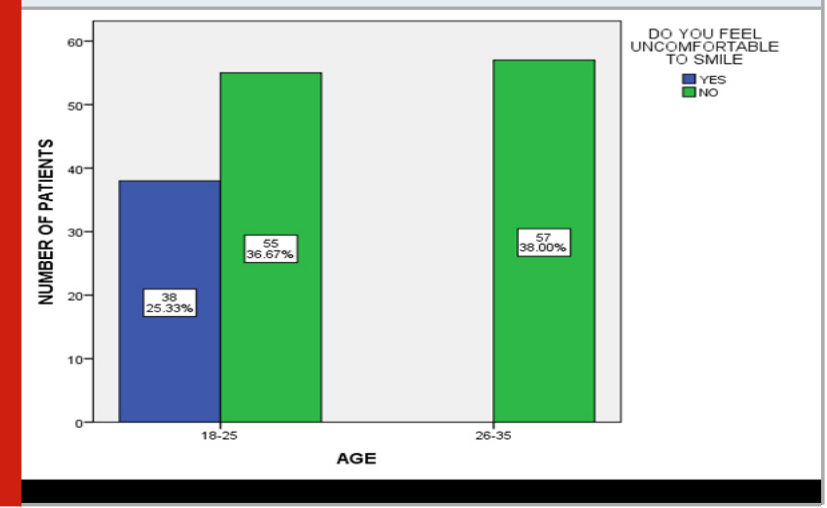

On statistically analysing the association between patients' awareness about their gingival pigmentation among gender, $29.33 \%$ under 18-25 years felt gingival pigmentation affected the confidence, $40.67 \%$ of males and $37.33 \%$ of females were about their gingival pigmentation. There was a statistically significant 
association between patients' awareness about their gingival pigmentation among gender, $\mathrm{p}$ value $=0.000$ [Figure 4]. On statistically analysing the association between patients' interaction with others among gender, $12.67 \%$ of females felt gingival pigmentation limited their interaction with others. There was a statistically significant association between patients' interaction with others among gender, $p$ value $=0.000$ [Figure 5]. On statistically analysing the association between patients' willingness to undergo treatment among gender, $10.67 \%$ of males and $8.67 \%$ of females were willing to undergo treatment for gingival pigmentation. There was no statistically significant association between patients' willingness for treatment among gender , $\mathrm{p}$ value $=0.152$ [Figure 6].

Figure 3: Bar graph shows the association between patients' confidence and different age groups. $\mathrm{X}$ axis - age in years ; $Y$ axis - number of patients. 29.33\% under 1825 years (blue) felt gingival pigmentation affected their confidence. There was a statistically significant association found. (Pearson chi square $=38.162 \mathrm{a}, \mathrm{p}$ value $=0.000$ )

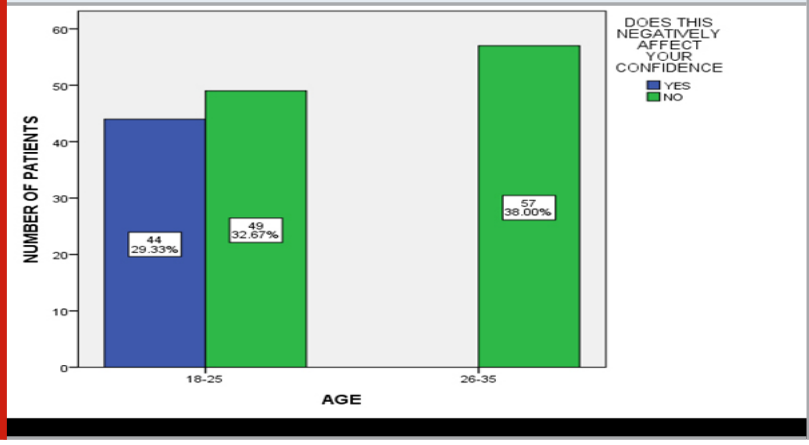

Figure 4: Bar graph shows the association between patients' awareness about their gingival pigmentation among gender. $\mathrm{X}$ axis -gender (males / females); $\mathrm{Y}$ axis number of patients. $40.67 \%$ of males (blue) and $37.33 \%$ females were aware about their gingival pigmentation. There was a statistically significant association found. (Pearson chi square $=16.785 a, p$ value $=0.000$ )

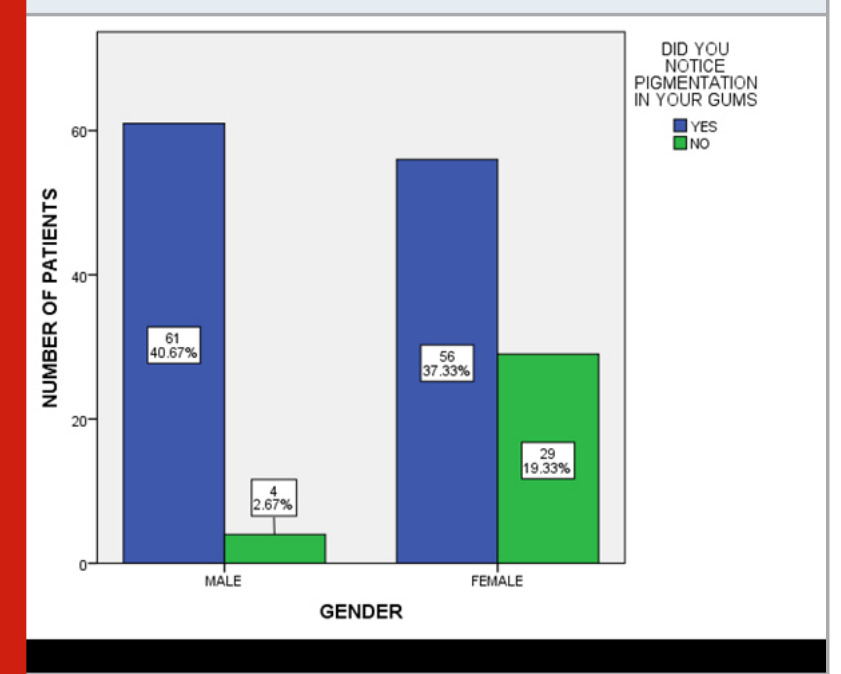

Figure 5: Bar graph shows the association between patients' interaction with others among gender. $\mathrm{X}$ axis -gender (males / females); Y axis - number of patients. $12.67 \%$ females felt gingival pigmentation limited their interaction with others. There was a statistically significant association found. (Pearson chi square $=16.637 \mathrm{a}, \mathrm{p}$ value $=0.000$ )

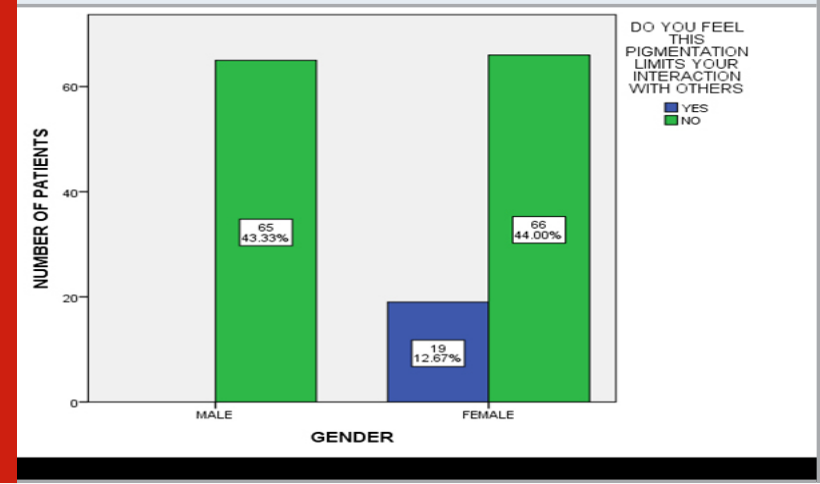

Figure 6: Bar graph shows the association between patients' willingness to undergo treatment for gingival pigmentation among gender. $\mathrm{X}$ axis -gender (males / females); $Y$ axis - number of patients. $10.67 \%$ of males (blue) and $8.67 \%$ of females (blue) were willing to undergo treatment for gingival pigmentation. There was no statistically significant association found. (Pearson chi square $=2.052 \mathrm{a}, \mathrm{p}$ value $=0.152$ )

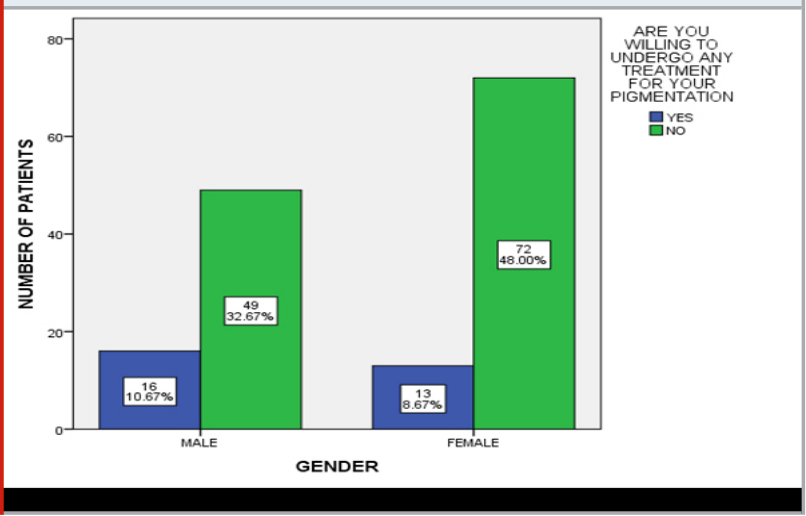

In our study, gingival pigmentation was in a higher prevalence among 18-25 years patients and was seen in a higher prevalence among females. Previous study has shown a gingival pigmentation among 18-35 years and a higher prevalence among males than females (Balaji, Manikandan and Ramsundar, no date). Studies done by Rakhewar et al and Ponnaiyan et al , there was no gender predilection among patients with gingival pigmentation. (Ponnaiyan, Anusha and Gomathy, 2013; Rakhewar, Patil and Thorat, 2016)Our findings are in contrast with the previous study. The possible reason would be due to the ethnicity and variation in geographic location. In our study, a higher prevalence of patients were aware about gingival pigmentation and have noticed the pigmentation in their gingiva. Study done by Grover has shown patients were aware about their 
gingival pigmentation and requested treatment for the same.(Grover et al., 2014).

In our study, younger adults under age 18-25 years responded that gingival pigmentation limited their interaction with peers and also lack of confidence. Previous study was conducted among 18-23 years students which showed that 59.3\% were concerned about their gingival pigmentation while 75\% of them considered dark coloured gingiva as unattractive.(Goswami et al., no date) In our study, females felt uncomfortable to smile and also felt that gingival pigmentation limited their interaction with others. While males and females were aware about gingival pigmentation but males were more willing for the treatment than females.

In our study about $19.3 \%$ were willing to undergo treatment. Study done by Goswami et al showed 54.7\% of the study population were willing to undergo treatment for gingival pigmentation.(Goswami et al., no date). Our findings are in contrast with the previous study. The possible reasons would be that they are fine with their appearance or they are being cultural or they are in a financial deficit to undergo procedures. The limitation of the study would be that it was a survey conducted among patients with gingival pigmentations. Few of the respondents would not have not felt encouraged to provide accurate, honest answers. There are chances for the patients of not feeling comfortable providing answers that present themselves unknown. The sample size of the study was smaller which could define the generalised population. And so multicentric surveys can be conducted on a larger population.

\section{CONCLUSION}

Within the limitations of the present study, $81.3 \%$ were aware of the gingival pigmentation and $25.3 \%$ felt uncomfortable with their esthetics while smiling. $19.3 \%$ of the study population were willing to undergo treatment for pigmentation while $87.3 \%$ were not affected with social interactions. Younger adults had more esthetic concern when compared to adolescents. Males were more willing to undergo treatment when compared to females.

Authors Contribution: Prashaanthi.N contributed acquisition of data, analysis, literature collection and also in drafting the article and revising it critically for important intellectual content. Karthikeyan .G contributed in conception, the study design, interpretation of data, formatting, manuscript preparation, supervision and guidance.

\section{ACKNOWLEDGEMENTS}

We take pleasure to acknowledge our University for granting permission to utilize the patient records for data collection

Conflict of Interest: The authors declare that there is no conflict of interest

\section{REFERENCES}

Alasmari, D. S. (2018) 'An insight into gingival depigmentation techniques: The pros and cons', International journal of health sciences, 12(5), pp. 84-89.

Arikan, F. and Gürkan, A. (2007) 'Cryosurgical treatment of gingival melanin pigmentation with tetrafluoroethane', Oral surgery, oral medicine, oral pathology, oral radiology, and endodontics, 103(4), pp. 452-457.

Arjunkumar, R. (2018) 'Nanomaterials for the Management of Periodontal Diseases', in Chaughule, R. S. (ed.) Dental Applications of Nanotechnology. Cham: Springer International Publishing, pp. 203-215.

Balaji, V. R., Manikandan, D. and Ramsundar, A. (no date) 'Prevalence of Gingival Pigmentation Among A Diverse Population Of Madurai--A Clinical Study' Available at: https://www.wjasr.in/uploads/150/5992_ pdf.pdf.

Esen, E. et al. (2004) 'Gingival melanin pigmentation and its treatment with the CO2 laser', Oral surgery, oral medicine, oral pathology, oral radiology, and endodontics, 98(5), pp. 522-527.

Ezhilarasan, D., Apoorva, V. S. and Ashok Vardhan, N. (2019) 'Syzygium cumini extract induced reactive oxygen species-mediated apoptosis in human oral squamous carcinoma cells', Journal of oral pathology At medicine: official publication of the International Association of Oral Pathologists and the American Academy of Oral Pathology, 48(2), pp. 115-121.

Goswami, V. et al. (no date) 'Knowledge, attitude and perception of gingival pigmentation among students aged 18-23 Years in UP, India', researchgate.net. Available at: https://bit.ly/306pLV5

Grover, H. S. et al. (2014) 'Evaluation of patient response and recurrence of pigmentation following gingival depigmentation using laser and scalpel technique: A clinical study', Journal of Indian Society of Periodontology, 18(5), pp. 586-592.

Hatch, C. L. (2005) 'Pigmented lesions of the oral cavity', Dental clinics of North America, 49(1), pp. 185-201, ix $-\mathrm{X}$.

Jain, M. and Nazar, N. (2018) 'Comparative Evaluation of the Efficacy of Intraligamentary and Supraperiosteal Injections in the Extraction of Maxillary Teeth: A Randomized Controlled Clinical Trial', The journal of contemporary dental practice, 19(9), pp. 1117-1121.

Kaarthikeyan, G., Jayakumar, N. D. and Sivakumar, D. (2019) 'Comparative Evaluation of Bone Formation between PRF and Blood Clot Alone as the Sole SinusFilling Material in Maxillary Sinus Augmentation with the Implant as a Tent Pole: A Randomized Split-Mouth 
Study', Journal of long-term effects of medical implants, 29(2), pp. 105-111.

Kavarthapu, A. and Malaiappan, S. (2019) 'Comparative evaluation of demineralized bone matrix and type II collagen membrane versus eggshell powder as a graft material and membrane in rat model', Indian journal of dental research: official publication of Indian Society for Dental Research, 30(6), pp. 877-880.

Kavarthapu, A. and Thamaraiselvan, M. (2018) 'Assessing the variation in course and position of inferior alveolar nerve among south Indian population: A cone beam computed tomographic study', Indian journal of dental research: official publication of Indian Society for Dental Research, 29(4), pp. 405-409.

Murthykumar, K., Arjunkumar, R. and Jayaseelan, V. P. (2019) 'Association of vitamin D receptor gene polymorphism (rs 10735810) and chronic periodontitis', Journal of investigative and clinical dentistry, 10(4), p. e12440.

Peeran, S. W. et al. (2014) 'Gingival pigmentation index proposal of a new index with a brief review of current indices', European journal of dentistry, 8(2), pp. 287-290.

Ponnaiyan, D., Anusha, J. A. and Gomathy, L. (2013) 'The correlation of skin color and gingival pigmentation patterns in a group of South Indians in Tamil Nadu, India', SRM Journal of Research in Dental Sciences, p. 54. doi: 10.4103/0976-433x.120178.

Rakhewar, P. S., Patil, H. P. and Thorat, M. (2016) 'Identification of gingival pigmentation patterns and its correlation with skin color, gender and gingival phenotype in an Indian population', Indian Journal of Multidisciplinary Dentistry. Medknow Publications and Media Pvt. Ltd., 6(2), p. 87.

Ramamurthy, J. and Mg, V. (2018) 'Comparison of effect of hiora mouthwash versus chlorhexidine mouthwash in gingivitis patients: a clinical trial', Asian J Pharm Clin Res, 11(7), pp. 84-88.

Ramesh, A. et al. (2018) 'Comparative estimation of sulfiredoxin levels between chronic periodontitis and healthy patients - A case-control study', Journal of periodontology, 89(10), pp. 1241-1248.

Ramesh, A. et al. (2019) 'Esthetic lip repositioning: A cosmetic approach for correction of gummy smile - A case series', Journal of Indian Society of Periodontology, 23(3), pp. 290-294.

Ramesh, A., Ravi, S. and Kaarthikeyan, G. (2017) 'Comprehensive rehabilitation using dental implants in generalized aggressive periodontitis', Journal of Indian Society of Periodontology, 21(2), pp. 160-163.

Ravi, S. et al. (2017) 'Additive Effect of Plasma Rich in Growth Factors With Guided Tissue Regeneration in Treatment of Intrabony Defects in Patients With Chronic Periodontitis: A Split-Mouth Randomized Controlled Clinical Trial', Journal of periodontology, 88(9), pp. 839-845.

Sedeh, S. A., Badihi, S. and Esfahaniyan, V. (2014) 'Comparison of recurrent rate of gingival pigmentation after treatment by liquid nitrogen and cryoprob in 18 months follows-up', Dental research journal, 11(5), pp. 592-598.

Shahna, N. et al. (2019) 'Gingival pigmentation: A review of literature'. oraljournal.com. Available at: http://www.oraljournal.com/pdf/2019/vol5issue2/ PartB/4-4-59-770.pdf.

Vijayashree Priyadharsini, J. (2019) 'In silico validation of the non-antibiotic drugs acetaminophen and ibuprofen as antibacterial agents against red complex pathogens', Journal of periodontology, 90(12), pp. 1441-1448. 